\title{
Wind power system for domestic installations
}

\author{
I. Mény, P. Enrici, JJ. Huselstein, D. Matt \\ Laboratoire d'électrotechnique de Montpellier (LEM) \\ Université Montpellier II \\ CC 079- Place Eugène Bataillon \\ 34095 Montpellier Cedex 5 (France) \\ phone:+33 467 149709, fax:+33 467 042130, e-mail: meny@univ-montp2.fr
}

\begin{abstract}
This paper describes the simulation and testing of a low power wind system including a vernier reluctance magnet machine (VRMM), used as a direct-driven generator. The aim is to propose the design and control of the electrical part of a domestic wind power installation. We want in particular investigate the benefits and limitations due to the use of the VRMM in this system.

We first present the structure and working equations of the VRMM and the AC/DC converters associated with it. Equations used to model VRMM and PWM rectifier in a d,q rotating frame are then detailed. A Simulink model of the system including the wind turbine is proposed. We show simulation results : we compare two methods used to drive the VRMM in order to reach the maximum power point of the turbine.

The design of a test bench is also presented. In this one, the wind turbine is emulated by a DC machine. The drives of the DC machine and of the VRMM are realized with the help of a D-Space board. With this bench, we study the association of VRMM with two different AC/DC converters. We finally foresee the later developments of the system.
\end{abstract}

\section{Key words}

Low power wind system, direct-driven generator, modelling, simulation, test-bench

\section{Introduction}

The LEM is located in Languedoc-Roussillon whose wind potential is one of the most important in Europe. (Figure 1)

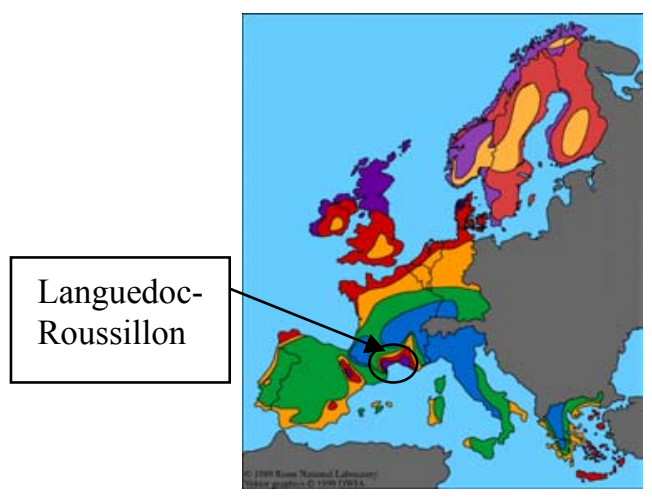

Fig.1 : wind resources at $50 \mathrm{~m}$ above ground level [1] (the darkest zones tally with the strongest winds)
This characteristic has led the Region to support projects concerning wind energy, notably for domestic installations of low power range (about $10 \mathrm{~kW}$ ). The LEM tries therefore to bring improvements in this type of wind energy conversion chains, including horizontal or vertical axis turbines. Our work focuses especially on the generator and its association with AC/DC converters.

\section{The energy conversion chain}

\section{A. Utilization of produced energy}

In order to support innovation in wind energy, French electricity national supplier EDF purchases electricity produced by wind turbines at attractive prices : even for low power installations, it can be more interesting to sale produced energy rather than to use it directly. For this reason, we foresee a grid connection of the power system. Independently of these financial aspects, low power wind turbines are meant for autonomous utilization, especially in locations where grid can not be installed. A storage system, essential for this application, must therefore be associated with the system.

\section{B. Directly driven generator}

In the low power wind systems, the electromechanical conversion is realized principally by the classical induction machine. As the turbine speed doesn't exceed $700 \mathrm{rpm}$, it is necessary to use a gearbox to reach the nominal speed of the generator, which is often equal to $1500 \mathrm{rpm}$.

There is a great interest in direct drive machines for lower maintenance, acoustic noise, mass, losses and cost $[2,3]$. In our power system, we want to study the utilization of a particular synchronous machine : the Vernier Reluctance Magnet Machine (VRMM) as a directly driven generator. The overall structure of our power system will therefore be the one showed in Figure 2. 


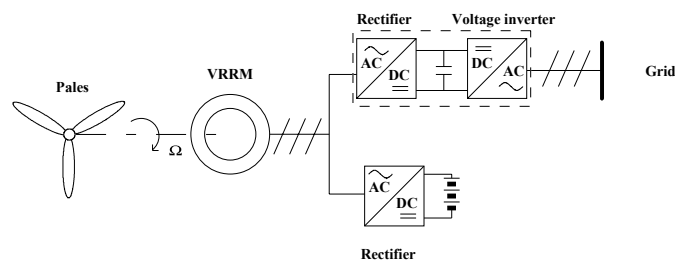

Fig. 2 : structure of the power system

\section{The vernier reluctance magnet machine (VRMM)}

The reluctance magnet machine we present in this article is an evolution of classical reluctance machine. As a magnet machine, its interest is mainly for low power applications we want to focus on.

Thanks to a simple structure presented in figure 3, the Vernier effect allows to carry out an electromechanical conversion at high frequency and with high mass torque [4].

The stator of a VRMM is almost identical with a standard cylindrical machine with three-phrase windings: when supplied by a three-phase current system, it creates a rotating magnetic field whose rotation speed is :

$$
\Omega_{\mathrm{s}}=\omega / \mathrm{p}
$$

with $\omega$ being the pulsation of current and $p$ the number of stator poles.

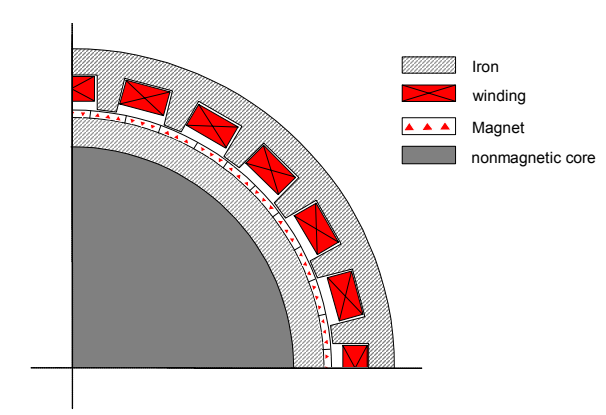

Fig.3. VRMM structure

The difference lies in absence of slots' isthmus in order to obtain vernier effect. In the structure we study in LEM, rotor field is produced by $\mathrm{Nr}$ pairs of surface-mounted magnets.

The working condition for this machine comes from the fact that the distributions of rotor and stator fields have the same periodicity, which results in the equation :

$$
\mathrm{p}=\left|\mathrm{N}_{\mathrm{r}}-\mathrm{N}_{\mathrm{s}}\right|
$$

Ns being the number of stator teeth.

As $\Omega \mathrm{r}$ is the rotor rotating pulsation ( $\mathrm{rad} / \mathrm{s}$ ), the frequency of the electromotive force is related to the number of magnet pairs by the expression :

$$
\mathrm{f}=\frac{\Omega_{\mathrm{r}} \cdot \mathrm{N}_{\mathrm{r}}}{2 \pi}
$$

Studies showed that the behavior of the VRMM is identical with a classical synchronous machine with smooth rotor [5], the phasor diagram of the VRMM used as a generator will therefore look like the one showed in figure 4 . The main difference is that the frequency is not related with the number of stator poles any more. This structure enables to realize machines with high torque versus weight ratio and the design of which is simpler than a multipole machine.

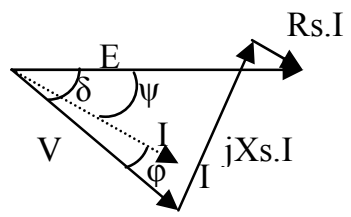

Fig. 4. Phasor diagram of the VRMM

- E: emf. The emf amplitude varies linearly versus speed and contains very few harmonics (see figure 5)

- Xs: synchronous reactance

- V: phase to ground voltage

- I: stator current

According with this diagram, the expression of the electro-magnetic power is :

$$
\mathrm{P}_{\mathrm{e}}=3 \mathrm{EI} \cos (\psi)=3 \mathrm{VI} \cos (\varphi)=\frac{3 \mathrm{EV}}{\mathrm{Xs}} \sin (\delta)(4)
$$

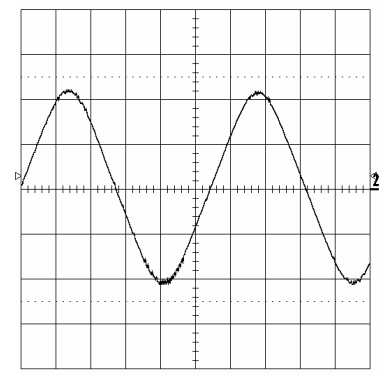

Fig.5. emf induction at $1000 \mathrm{rpm}$

The high mass torque of the VRMM makes it attractive for all direct-drive applications : it can be used as an inwheel-motor for electric vehicles. [6]

\section{Electronic converters associated with the VRRM}

In wind power applications, as the frequency and the emf are proportionnal to the speed, synchronous generators are associated with $\mathrm{AC} / \mathrm{DC}$ converters, both for low power or high power wind turbines.

One of our objects is to study the association of the VRMM with different AC/DC converters, notably the most standard ones : diode bridge rectifier and PWM rectifier (figure 6).

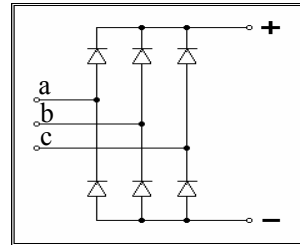

a) diode bridge

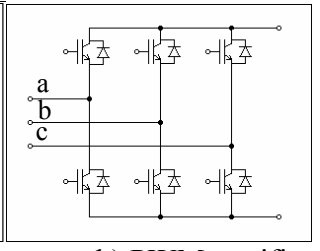

b) PWM rectifier
Fig. 6 : three phases rectifiers

A PWM rectifier will enable to vary the speed of the turbine and then to fit at best the wind speed in order to raise production of the turbine to a maximum. 
Considering the high cyclic inductance of the VRMM, diode bridge rectifier imposes working conditions that are far from the optimum ones : as can be seen in figure 7 , the angle $\psi$ become large, thus reducing electromagnetic power for a given current.

PWM rectifier, by making it possible to work with the electromotive force in phase with the stator current and by absorbing near sinusoidal current waveforms, will then bring additional benefits.
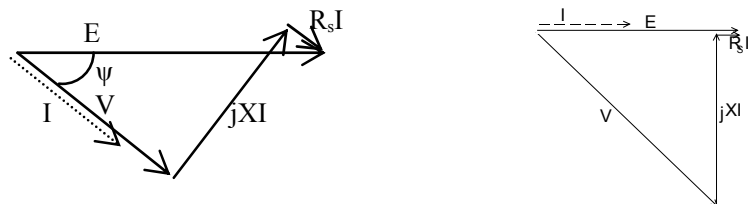

Fig. 7 : phasor diagram for the fundamental with diode bridge rectifier (left) and with PWM rectifier

To compare the behavior of the conversion chain with these two rectifiers, we first study the system showed in figure 8.

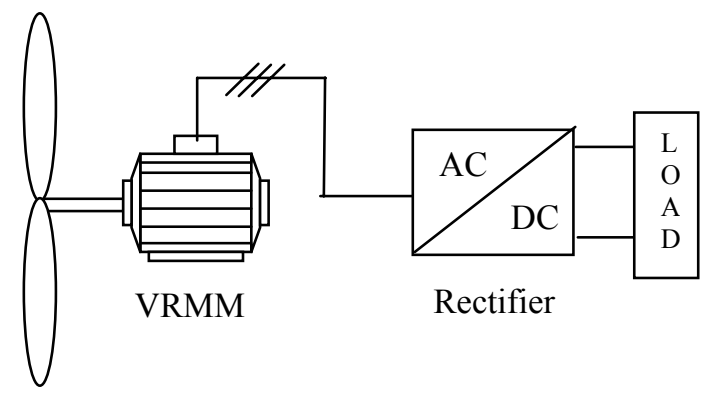

Turbine

Fig. 8 : VRMM/rectifier association

\section{Modeling and simulation of the system}

\section{A. VRMM Model}

The system, when used with a PWM rectifier, will be controlled in a d,q reference frame attached to the rotor. In order to test the control laws, the system was first modeled and simulated with Matlab/Simulink in this reference frame. The machine equations become [7]:

$$
\begin{aligned}
& \mathrm{v}_{\mathrm{sd}}=\mathrm{R}_{\mathrm{s}} \cdot \mathrm{i}_{\mathrm{sd}}+\frac{\mathrm{d} \varphi_{\mathrm{sd}}}{\mathrm{dt}}-\omega_{\mathrm{e}} \cdot \varphi_{\mathrm{sq}} \\
& \mathrm{v}_{\mathrm{sq}}=\mathrm{R}_{\mathrm{s}} \cdot \mathrm{i}_{\mathrm{sq}}+\frac{\mathrm{d} \varphi_{\mathrm{sq}}}{\mathrm{dt}}+\omega_{\mathrm{e}} \cdot \varphi_{\mathrm{sd}}
\end{aligned}
$$

where :

$\mathrm{v}_{\mathrm{sd}}$ and $\mathrm{v}_{\mathrm{sq}}$ are the $\mathrm{d}$ - and $\mathrm{q}$-axis stator voltages $\mathrm{i}_{\mathrm{sd}}$ and $\mathrm{i}_{\mathrm{sq}}$ are the $\mathrm{d}$ - and $\mathrm{q}$ - axis stator currents

$\mathrm{R}_{\mathrm{s}}$ is the per phase stator resistance, it is modified to take iron losses into account $\varphi_{\mathrm{sd}}$ and $\varphi_{\mathrm{sq}}$ are the $\mathrm{d}$ - and q-axis stator fluxes $\omega_{\mathrm{e}}$ is the stator electrical pulsation in $\mathrm{rad} / \mathrm{sec}$

The frame is chosen so the rotor flux $\varphi_{\mathrm{m}}$ is collinear with the d-axis :

$$
\varphi_{\mathrm{sd}}=\mathrm{L}_{\mathrm{sd}} \cdot \mathrm{i}_{\mathrm{sd}}+\varphi_{\mathrm{m}}
$$

$$
\varphi_{\mathrm{sq}}=\mathrm{L}_{\mathrm{sq}} \cdot \mathrm{i}_{\mathrm{sq}}
$$

$\mathrm{L}_{\mathrm{sd}}$ and $\mathrm{L}_{\mathrm{sq}}$ being the $\mathrm{d}$ - and $\mathrm{q}$-axis synchronous inductances of the stator, here equal. (surface mounted magnets)

The complete set of equations is then :

$$
\begin{gathered}
\mathrm{v}_{\mathrm{sd}}=\mathrm{R}_{\mathrm{s}} \cdot \mathrm{i}_{\mathrm{sd}}+\mathrm{L}_{\mathrm{sd}} \cdot \frac{\mathrm{di}_{\mathrm{sd}}}{\mathrm{dt}}-\omega_{\mathrm{e}} \cdot \mathrm{L}_{\mathrm{sq}} \cdot \mathrm{i}_{\mathrm{sq}} \\
\mathrm{v}_{\mathrm{sq}}=\mathrm{R}_{\mathrm{s}} \cdot \mathrm{i}_{\mathrm{sq}}+\mathrm{L}_{\mathrm{sq}} \cdot \frac{\mathrm{di}_{\mathrm{sq}}}{\mathrm{dt}}+\omega_{\mathrm{e}} \cdot \mathrm{L}_{\mathrm{sd}} \cdot \mathrm{i}_{\mathrm{sd}}+\omega_{\mathrm{e}} \cdot \varphi_{\mathrm{m}} \\
\mathrm{T}_{\mathrm{em}}=\mathrm{N}_{\mathrm{r}} \cdot \varphi_{\mathrm{m}} \cdot \mathrm{i}_{\mathrm{sq}} \\
\frac{\mathrm{d} \Omega}{\mathrm{dt}}=\frac{1}{\mathrm{~J}} \cdot\left(\mathrm{T}_{\mathrm{shaft}}-\mathrm{T}_{\mathrm{em}}-\mathrm{f} \cdot \Omega\right)
\end{gathered}
$$

$\mathrm{T}_{\mathrm{em}}$ is the electromechanical torque developed by the VRMM, $\mathrm{T}_{\text {shaft }}$ is the mechanical torque developed by the turbine and $\Omega$ is the rotor speed in $\mathrm{rad} / \mathrm{sec}$.

Remark : the VRMM available in LEM is a prototype not specifically designed for wind turbines. It can develop a $6 \mathrm{Nm}$ torque; in order to produce a maximum of about $500 \mathrm{~W}$, it will work at speeds near from $800 \mathrm{rpm}$, which is close to the speeds of wind turbines in this range of power.

This prototype has the following characteristics:

$$
\begin{aligned}
& \text { - } 4 \text { poles }: \mathrm{p}=2 \\
& \text { - } \mathrm{Ns}=24 \text { stator teeth } \\
& \text { - } \mathrm{Nr}=22 \text { pairs of magnets } \\
& \text { - emf coefficient : } 0.825 \mathrm{~V} / \mathrm{rad} / \mathrm{S} \\
& \text { - synchronous inductance }: 61.2 \mathrm{mH}
\end{aligned}
$$

\section{B. PWM rectifier model}

In order to avoid very long computing times and overflow of the memory, we use an average model for the PWM rectifier [8]:

$$
\begin{aligned}
\mathrm{v}_{\mathrm{wd}}= & \mathrm{v}_{\mathrm{sd}}+\mathrm{R}_{\mathrm{r}} \cdot \mathrm{i}_{\mathrm{sd}}+\mathrm{L}_{\mathrm{r}} \cdot \frac{\mathrm{di} \mathrm{sd}_{\mathrm{sd}}}{\mathrm{dt}}-\omega_{\mathrm{e}} \cdot \mathrm{L}_{\mathrm{r}} \cdot \mathrm{i}_{\mathrm{sq}} \\
\mathrm{v}_{\mathrm{wq}}= & \mathrm{v}_{\mathrm{sq}}+\mathrm{R}_{\mathrm{r}} \cdot \mathrm{i}_{\mathrm{sq}}+\mathrm{L}_{\mathrm{r}} \cdot \frac{\mathrm{di} \mathrm{sq}_{\mathrm{sq}}}{\mathrm{dt}}+\omega_{\mathrm{e}} \cdot \mathrm{L}_{\mathrm{r}} \cdot \mathrm{i}_{\mathrm{sd}} \\
& \mathrm{U}_{\mathrm{cc}} \cdot \mathrm{i}_{\mathrm{cc}}=\frac{3}{2} \cdot\left(\mathrm{i}_{\mathrm{sd}} \cdot \mathrm{v}_{\mathrm{wd}}+\mathrm{i}_{\mathrm{sq}} \cdot \mathrm{v}_{\mathrm{wq}}\right)
\end{aligned}
$$

where :

$\mathrm{v}_{\mathrm{wd}}$ and $\mathrm{v}_{\mathrm{wq}}$ are the $\mathrm{d}-$ and $\mathrm{q}-$ axis of the fundamental rectifier voltages

$\mathrm{L}_{\mathrm{r}}$ is the smoothing inductor connected between machine output and rectifier $\mathrm{i}_{\mathrm{cc}}$ is the DC link current

$\mathrm{R}_{\mathrm{r}}$ resistance in $\mathrm{L}_{\mathrm{r}}$ and two of the semiconductors switches

\section{Wind turbine model}

The model of VRMM is associated with a wind turbine model. It is a model deduced of a real turbine but modified in order to fit to characteristics of VRMM 
prototype. For wind speeds ranging from $5 \mathrm{~m} / \mathrm{s}$ to $12 \mathrm{~m} / \mathrm{s}$, the power versus rotor speed characteristic of this model is shown in figure 9.

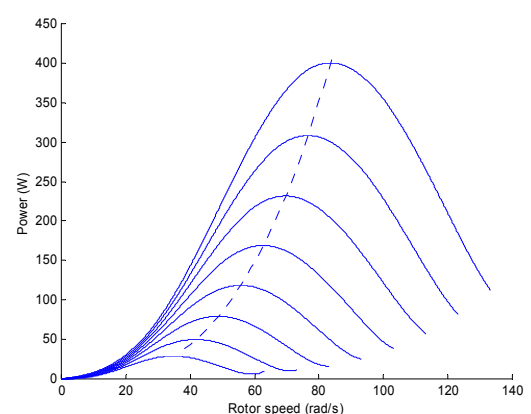

Fig. 9 : characteristic of wind turbine model

\section{Control principle}

The PWM rectifier is controlled in order to impose rotor speed (Fig. 10). As shown by eqn (12), $\mathrm{i}_{\text {sd }}$ does not contribute to torque production, $i_{\mathrm{dg}}$ should therefore be zero to minimize the resistive losses in VRMM. The speed controller gives a current reference $i_{\text {sqref }}$ to the rectifier controller, which maintains stator currents in phase with emf.

To eliminate the coupling terms between $\mathrm{d}$ and $\mathrm{q}$ axis (see eq (10) and (11)), the current controllers contain compensation terms. The $i_{\mathrm{sq}}$ controller contains an additional term to compensate the emf $\omega_{\mathrm{e}} \cdot \phi_{\mathrm{m}}$. In this case, current control is equivalent to control of two independent first order systems the transfer function of which is :

$$
\mathrm{G}_{\mathrm{i}}(\mathrm{p})=\frac{1}{\mathrm{R}_{\mathrm{s}}+\mathrm{L}_{\mathrm{sd}, \mathrm{q}} \cdot \mathrm{p}}
$$

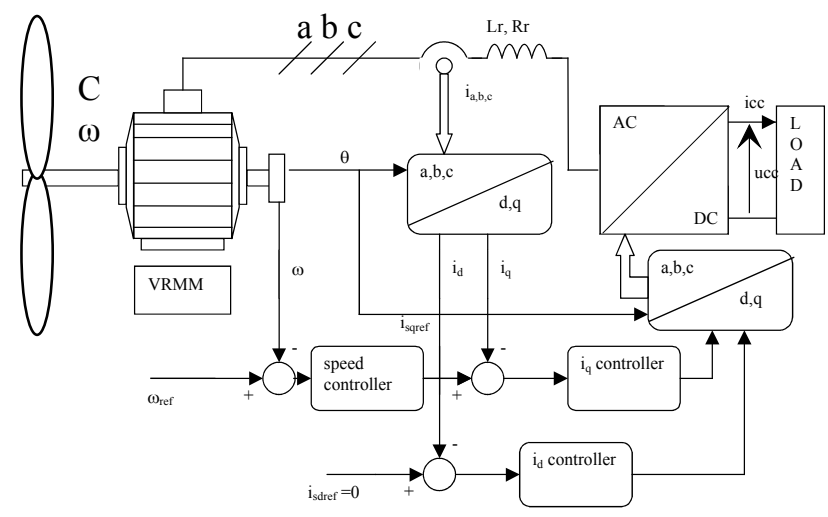

Fig. 10 : control principle

Remarks :

- in a further development of the system, the DC link voltage ucc will be controlled by a DC/AC gridconnected converter. The load used here is a capacity of $1100 \mu \mathrm{F}$ in parallel with a resistance. The DC link voltage is controlled with an IGBT which feeds the load when the voltage is sufficient. It is OFF when voltage is below $650 \mathrm{~V}$.
- the control is implemented both in Matlab/Simulink and for experiment in a d,q rotating frame. The aim is not to obtain high dynamic performances, which are unnecessary in this application. As we work at frequencies near to $400 \mathrm{~Hz}$, control in a stationary frame $(a, b, c)$ can introduce an important phase difference between references and actual currents, thus reducing the benefit of the control. Experimentally, we measured that this phase difference can reach $30^{\circ}$, which results in a drop of produced power of $14 \%$.

By using these models and these control principles, we obtain the complete model implemented in Simulink (figure 11).

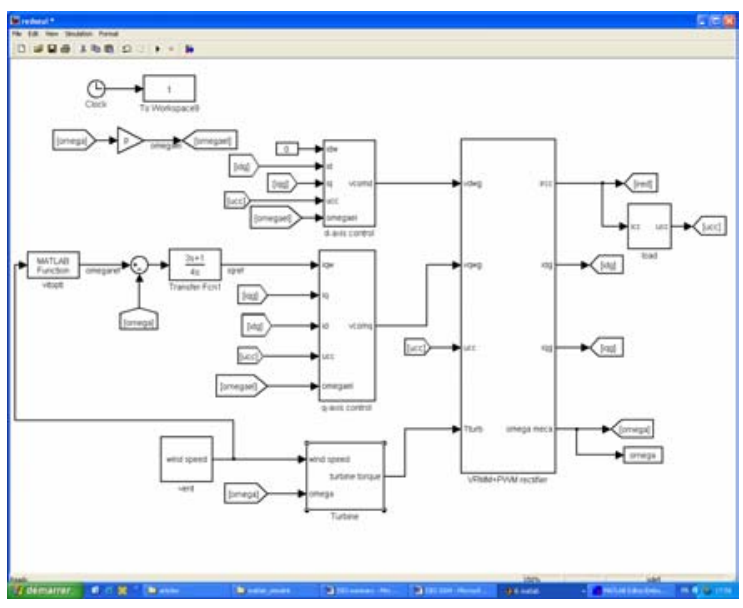

Fig.11 : Simulink model of the system

A purpose of this model is to test control methods of the generator so as to operate at best with the turbine. There are different ways to approach the maximum power point :

- in fig. 10, we do a speed control and we use the wind speed to compute $\omega_{\text {ref }}$ : we set the working point of the turbine to the optimum one for each wind speed; as a result, the turbine power follows the dotted line in figure 9.

- the former method, if employed with a real wind turbine, implies the use of an anemometer and an accurate knowledge of the turbine's characteristics. A failure of the anemometer would result in drop of power production, the utilization of this method is therefore not very realistic : we will test a control method working without any anemometer and use the former method as a reference.

A simple way to come close to the maximum power point is to use the torque versus rotation speed characteristic curves of the turbine for different wind speeds. (figure 12)

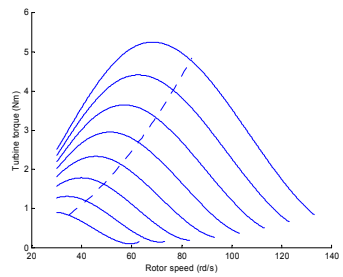

Fig.12 : torque versus rotor speed characteristic curves of the turbine 
The dotted line in fig.12 links the maximum power points. We can see that these points are located in the stable part of the characteristic, where :

$$
\frac{\mathrm{d} \Gamma}{\mathrm{d} \Omega} \leq 0
$$

To set the working point on this dotted line, we can do a torque control where $\Gamma_{\text {ref }}$ (or isq ref $)$ is computed by using a speed measurement or, preferably, a speed estimation. These two methods : speed control with anemometer and torque control without anemometer were compared for a simple wind profile showed in figure 13, where the important points a, b, c, d are indicated; it is quite representative of the frequent gust winds observed in urban areas. We used two different values for turbine inertia so that $\mathrm{J} 2=4 . \mathrm{J} 1$. The results are shown in figure 14 and 15 . We can see that the method of torque control is less efficient (power difference between $\mathrm{c} 1$ and $\mathrm{c} 2$ ) when the inertia rises, which limits it to small turbines.

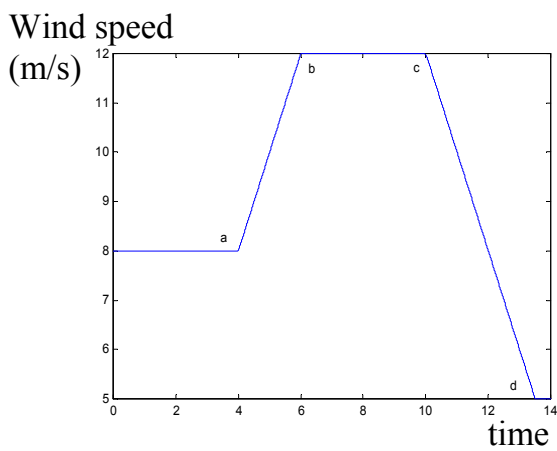

Mechanical

Fig. 13 : wind profile

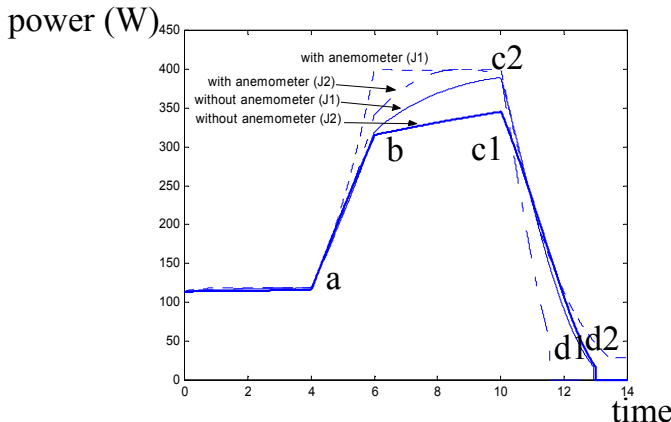

Fig.14 : turbine power with different values of inertia

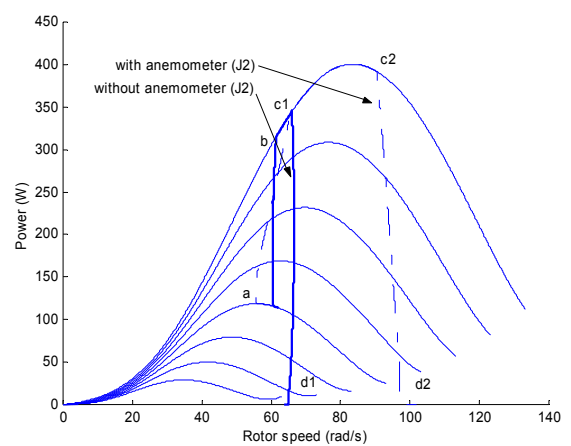

Fig. 15 : turbine power vs rotor speed for J2

\section{Design of a test bench}

\section{A. Objectives}

We want to realize an experimental bench to test the VRMM prototype available in laboratory as a generator for wind turbines. Having considered the investment implied by a complete turbine installation, we decided on a more economic solution : we can put a direct-current machine in place of the turbine [9]. This DC machine is controlled so as to behave like a wind turbine (figure 16). It enables besides to impose various wind profiles without being dependent on the climatic conditions. We can also adapt our simulated turbine to the generator characteristics : in our case, we will use curves showed in figure 7. Moreover, it is easier to use instrumentation with this experimental device available within the laboratory.

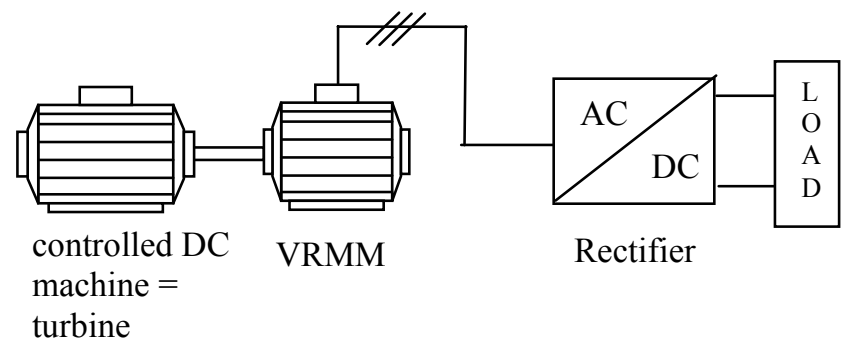

Fig. 16: general sketch of the test bench

\section{B. Implementation}

For the implementation of the test bench, we use a DSpace board to control the VRMM and to simulate the wind turbine. This board includes a DSP programmed with the help of a Simulink model. The principle is shown in figure 17, and the bench in figure 18 .

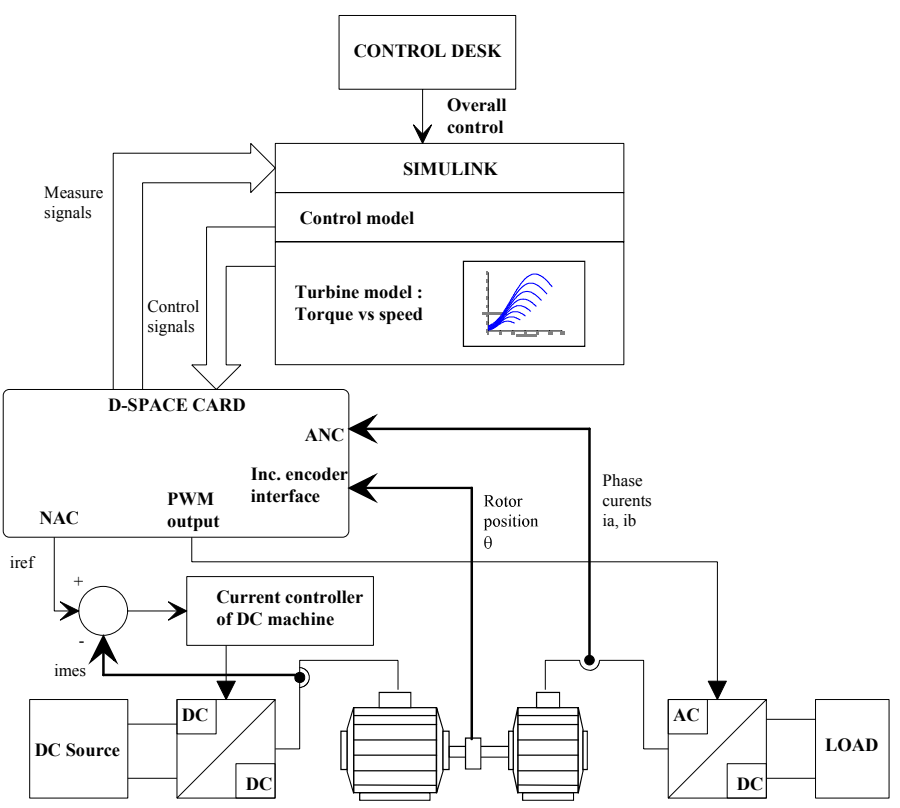

Fig. 17 : implementation 


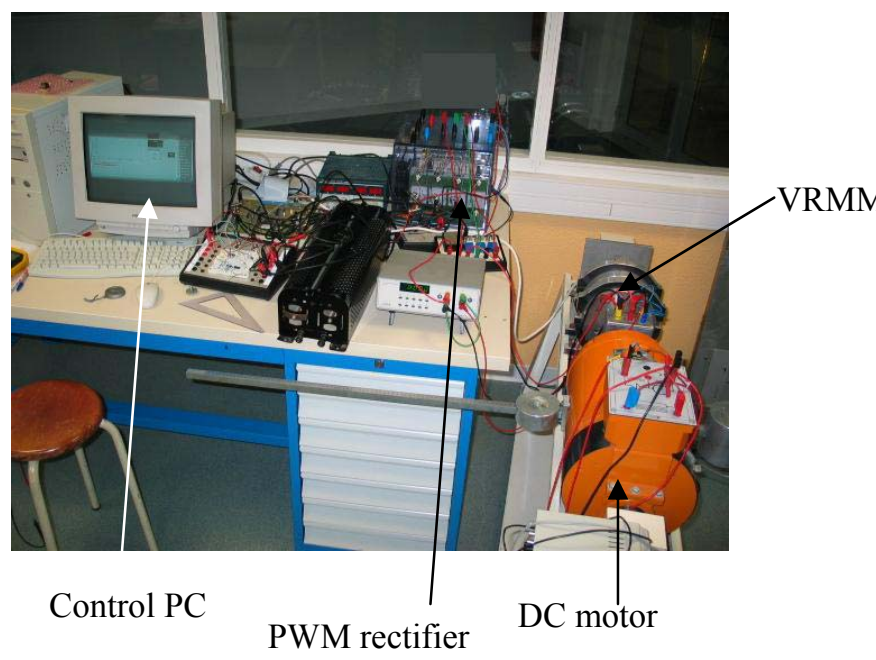

Fig. 18 : the test bench

\section{Experimental results}

The bench was used to compare the association of the VRMM with diode bridge rectifier and PWM rectifier. For the diode bridge rectifier, considering the phasor diagram in figure 7 and neglecting the phase resistance $\mathrm{R}_{\mathrm{s}}$, we can deduce that the maximum power will be reached when :

$$
\mathrm{V}=\mathrm{X} \cdot \mathrm{I}=\frac{\mathrm{E}}{\sqrt{2}}
$$

We realized an impedance match so that VRMM verifies this relation for each wind speed. As regards PWM rectifier, it was controlled according to principle showed in figure 8 . The mechanical power produced by the turbine is plotted in figure 19. We did not impose dynamical variations of the wind speed : measurements are made at stable wind speeds.

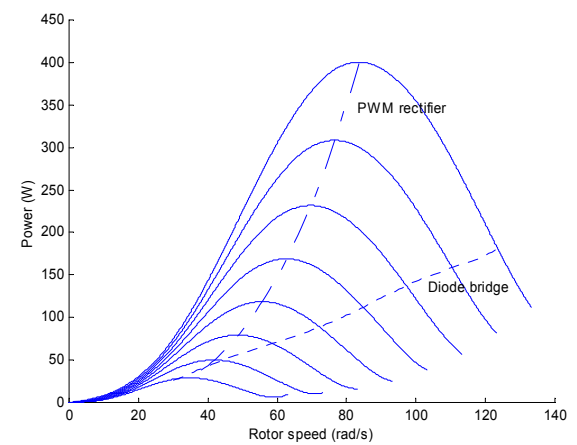

Fig. 19: mechanical power produced by the turbine with the two rectifiers

We can now quantify the difference between the two rectifiers : if the powers produced are almost equal at low wind speeds, the power produced with PWM rectifier is more than twice the power produced with the diode bridge at 11 or $12 \mathrm{~m} / \mathrm{s}$. This underutilization of the turbine capabilities due to the diode bridge makes this one not very attractive, in spite of its low cost and simplicity.

\section{Perspectives}

The turbine characteristic curves we used here were inferred from approximate data given by a manufacturer, and the wind profile is theoretical. We foresee to use the bench with precise measurements made on a real site to test control laws.

We want also design a more powerful VRMM adapted to wind turbines, notably for the rotating speed. The aim is to develop a complete energy conversion chain using as few measurement devices as possible to improve the reliability of the chain.

\section{Conclusion}

The VRMM, with its high mass torque and simple structure, has assets to realize a direct-drive in a wind energy system. As it behaves like a classical synchronous machine with smooth rotor, we could model an energy conversion chain including it. With this model, we tested control methods of the VRMM in conditions that are representative of those encountered in urban areas, for which our wind system is destined. Thanks to the test bench that we implemented in the laboratory, we could note that electrical properties of the VRMM make it incompatible with a diode rectifier.

\section{References}

[1] http://www.windpower.org

[2] A. Grauers, "Efficiency of three wind energy generator systems", IEEE Trans. on Energy conversion, vol.11, n³, pp 650-655, September 1996.

[3] B.J. Chalmers, W. Wu, E. Spooner, "an axial-flux permanent- magnet generator for a gearless wind energy system", IEEE Trans. on Energy conversion, vol.14, n², pp 251-257, June 1999

[4] Daniel Matt, J.F. Llibre, "Comparaison des performances des machines à réluctance variables à aimants. Maximisation $\mathrm{du}$ couple massique ou $\mathrm{du}$ couple volumique. ", Journal de Physique, pp 1621-1641, october 1995

[5] J-F. Llibre, "Etude d'une structure de machine synchrone cylindrique vernier à aimants permanents.", Thèse de Doctorat, INPT, September 1997.

[6] P. Enrici, J. Fadat, D. Matt, "Dimensionnement d'un moteur roue pour un scooter électrique", in Proc. EF'2001, pp 335341, November 2001.

[7] Jens Birk, Ewen Ritchie, "Model of permanent magnet generator feeding a network through an AC-DC-AC converter ", in Proc. CICEM'95, pp. 976-981, Aug. 1995

[8] G. Séguier, "les convertisseurs de l'électronique de puissance", tome 5, éditions tech \& doc, 1991

[9]Cristian Nichita, "Etude et développement de structures et lois de commande numériques pour la réalisation d'un simulateur de turbine éolienne de $3 \mathrm{~kW}$ ", Thèse de doctorat, Université du Havre, June 1995. 